\title{
Improving olive mechanical harvesting using appropriate natural frequency
}

\author{
Ahmed Alzoheiry, ${ }^{1,2}$ Mohamed Ghonimy, ${ }^{1,3}$ Eid Abd El Rahman, ${ }^{3}$ Ossama Abdelwahab, ${ }^{3}$ \\ Ahmed Hassan ${ }^{3}$ \\ ${ }^{1}$ Department of Plant Production and Protection, College of Agriculture and Veterinary Medicine, Qassim University, \\ Buraydah, Saudi Arabia; ${ }^{2}$ Department of Natural Resources and Agricultural Engineering, Faculty of Agriculture, \\ Damanhour University, Damanhour, Egypt; ${ }^{3}$ Department of Agricultural Engineering, Faculty of Agriculture, Cairo \\ University, Cairo, Egypt
}

\begin{abstract}
The good performance of olive mechanical harvesting by shaking depends on the suitable values of limb vibrator operating parameters (frequency and amplitude). Mathematical models of a single degree of freedom (S.D.F.M) and two degrees of freedom (T.D.F.M) were used to estimate the natural frequency $\left(F_{N}\right)$ of olive fruit stem system. The results from these models indicated that the $F_{N}$ values were $33.9,31.9$, and $28.0 \mathrm{~Hz}$ for the full mature stage, half-ripe olive, and full-ripe olive respectively. Branch vibrator was operated at three levels of frequency 25, 30 and 35 $\mathrm{Hz}$ and 3 levels of amplitude 25,30 and $35 \mathrm{~mm}$ at a vibration time of $10 \mathrm{~s}$. Measurements covered the fruit removal percentage $(F R P)$ and degree of full-ripe fruit selectivity $(D S)$. The results showed that the maximum $F R P$ value, 90.6\%, was achieved at a frequency of $35 \mathrm{~Hz}$ and amplitude of $25 \mathrm{~mm}$ while the maximum $D S$ value, $78.58 \%$, was obtained at $25 \mathrm{~Hz}$ frequency and $25 \mathrm{~mm}$ amplitude.
\end{abstract}

\footnotetext{
Correspondence: Ahmed Alzoheiry, Department of Plant Production and Protection, College of Agriculture and Veterinary Medicine, Qassim University, Buraydah, Saudi Arabia.

E-mail: alzoheiry@gmail.com
}

Key words: Fruit removal; natural frequency; olive; selectivity; vibration.

Acknowledgements: the authors wishes to express here sincere thanks and appreciation to Prof. Dr. Diaa A. El-Rayes, Professor of Horticulture, Collage of Agriculture and Veterinary Medicine, Qassim Univ., KSA., for his continues help support.

Received for publication: 6 February 2020

Accepted for publication: 13 June 2020.

${ }^{\circ}$ Copyright: the Author(s), 2020

Licensee PAGEPress, Italy

Journal of Agricultural Engineering 2020; LI:1057

doi:10.4081/jae.2020.1057

This article is distributed under the terms of the Creative Commons Attribution Noncommercial License (by-nc 4.0) which permits any noncommercial use, distribution, and reproduction in any medium, provided the original author(s) and source are credited.

\section{Introduction}

The olive crop is considered one of the main crops in the Middle East. In the olive harvest and post-harvest operations, engineering theories and concepts were used to reach a high-quality product; fruits and oil (Leone et al., 2015; Beghi et al., 2017; Tamborrino et al., 2017; Aiello et al., 2019; Cappelli et al., 2019; Karimi et al., 2019). Harvesting is considered a crucial operation in the production of the olive crop. Fruit harvesting ooccurred either manually or mechanically. Generally, manual harvesting costs about $30-60 \%$ of the total production cost (Cicek, 2011). Mechanical harvesting is underway in some olive producing countries such as USA, Spain, Italy, and Greece, where economically feasible mechanical harvesting methods are being developed (Zipori et al., 2014). The manual harvesting was developed using hand-held harvester. The types of hand-held olive harvesters included beaters, combs, and hooks where harvesting is obtained by direct impact on the olive fruit or by vibration transmitted to the willowy branches (Deboli et al., 2014a). The productivity of hand-held olive harvester is about 5 times that of using the manual harvesting (Deboli et al., 2014b). The harvesting of ripe olive fruits only (using the vibrating manner) depends upon the good determination of vibration parameters such as frequency, amplitude, and vibration time (Bacenetti and De Luca, 2018). SolaGuirado et al. (2016) found that the increase in vibration frequency and/or vibration amplitude enhances harvest efficiency. The determination of the natural frequencies of the fruit stem system is the first step in successfully using a tree vibratory harvester. The natural frequencies of the system depend upon the mode shape, system dimensions, and material properties of the system (Hoshyarmanesh et al., 2017). Catalano et al. (2013) determined the elastic behaviour and the natural frequency of vibration of an olive tree harvested using tree trunk vibrator. They also determined the damping coefficients and the natural vibration modes. Castro-García et al. (2014) reported that the low harvesting efficiency values are not only owing to high fruit removal force, but also other variables such as tree training. Tree structure also play an important role in harvesting efficiency. Ghonimy (2006) derived a mathematical relationship to predict the suitable shaking amplitude of limb tree shaker. The derived equation correlates the pulling force, fruit mass ratio, stem length, shaking frequency and damping ratio to the shaking amplitude. Aiello et al. (2019) found that hand-held olive harvester can harvest more than $80 \%$ of the overall quantity of olives available per tree, but their performance is influenced by several factors related to the mechanical characteristics of the device and the features of the trees. Leone et al. (2015) found that the frequencies that maximized the olive fruit removal percentage ranged from 23 to $27 \mathrm{~Hz}$. They also reported that the optimal shaking time per one branch ranged from 6 to $8 \mathrm{~s}$. 
Using the suitable natural frequency for olive fruit stem leads to increasing both the fruit removal percentage and fruit selectivity with minimising tree damage.

Thus, the aim of this research was to determine the suitable level of the vibrator operating parameters (frequency and amplitude) of a hand-held olive harvester to obtain the maximum fullripe fruit removal percentage possible.

\section{Materials and methods}

This study was conducted during the 2017 season, on twentyyear-old Picual olive trees. Trees were planted at $4 \mathrm{~m}$ intervals between rows and $4 \mathrm{~m}$ intervals within rows $\left(625 \mathrm{trees}^{\mathrm{h}} \mathrm{ha}^{-1}\right)$. The trees were trained to a central leader system. This investigation was divided into three stages. The first stage was to determine the physical-mechanical properties of the fruit stem system, the second stage was to find the natural frequencies of the olive branch system using mathematical models of single and two degrees of freedom, and the third stage was about field experiments, using a branch vibrator.

\section{First stage}

Picual olive fruits were classified visually into three groups according to their maturity levels based on fruit skin and flesh colour (according to maturity index described by Guzmán et al. (2015). The selected maturity levels were as follows: i) Full-ripe fruits (all fruit skin colour was purple or black with all the flesh purple to the pit); ii) Half-ripe fruits (more than half of the fruit skin colour was turned red, purple or black); and iii) Full mature stage (skin colour of the fruit was yellow-green). For each maturity level, 100 olive fruit stem systems were randomly selected to determine fruit mass, fruit bulk density, stem elasticity constant, and the geometric properties of fruit and stem.

\section{Geometric properties}

Olive stem length and olive fruit dimensions were measured using a vernier caliper (accuracy of $0.1 \mathrm{~mm}$ ). The principal dimensions of olive fruit were determined assuming that the olive fruit has a nearly elliptical shape.

\section{Mass and bulk density}

Olive fruit mass was determined using a digital balance with

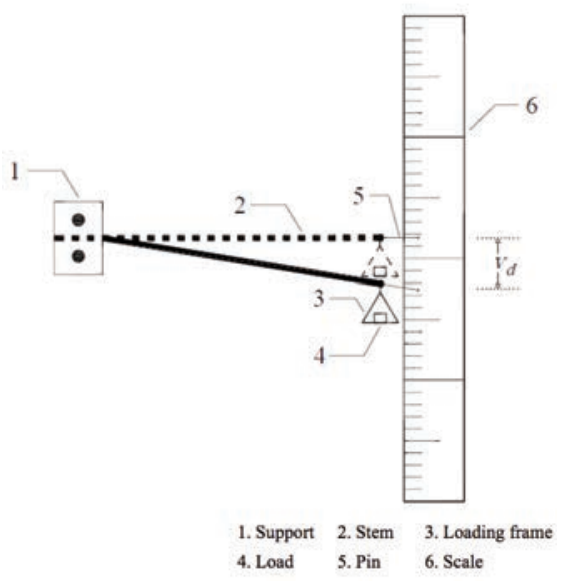

Figure 1. Schematic diagram for measuring the elasticity constant of stem. an accuracy of $1.0 \mathrm{~g}$. The bulk density of olive fruit was calculated by determining the mass of the fruit and its volume using volumetric calibration.

\section{Elasticity constant of stem}

Stem elasticity constant was determined using the beams general theory (Cai, 2016). The stem fruit system can be modelled as a cantilever beam loaded at its' end. The stem was fixed horizontally on the vertical plate by support (Figure 1). The stem was loaded $\left(L_{b}\right)$ with small weights ranging from 1 to $10 \mathrm{~g}$ at its end. These weights caused a vertical displacement (deflection) due to the spring-mass behaviour. The stem deflection was determined by measuring the vertical distance between the initial and final position of the stem end. The elasticity constant was calculated from Equation (1) (Ciro 2001).

$K_{1}=\frac{L_{b}}{v_{d}}$

Where:

$K_{l}=$ Elasticity constant of stem, $\mathrm{N} \cdot \mathrm{m}^{-1}$;

$L_{b}=$ Load in bending test, $\mathrm{N}$;

$v_{d}=$ Vertical displacement of stem in bending test, $\mathrm{m}$.

The stem rigidity value $(E I)$ was calculated using Equation (2) (Ciro, 2001).

$E I=\frac{K_{1} l^{3}}{3}$

Where:

$E I=$ Stem rigidity value, $\mathrm{N} \cdot \mathrm{m}^{2}$;

$l=$ Stem length, $\mathrm{m}$.

\section{Second stage}

Single degree of freedom and two degrees of freedom models were used to determine the natural frequency of the olive fruit stem system.

\section{Single degree of freedom model}

The olive fruit stem system in the case of a single degree of freedom model (S.D.F.M) is a beam loaded with a mass at its end, shown in Figure 2. In this model, the stem is the beam and the fruit

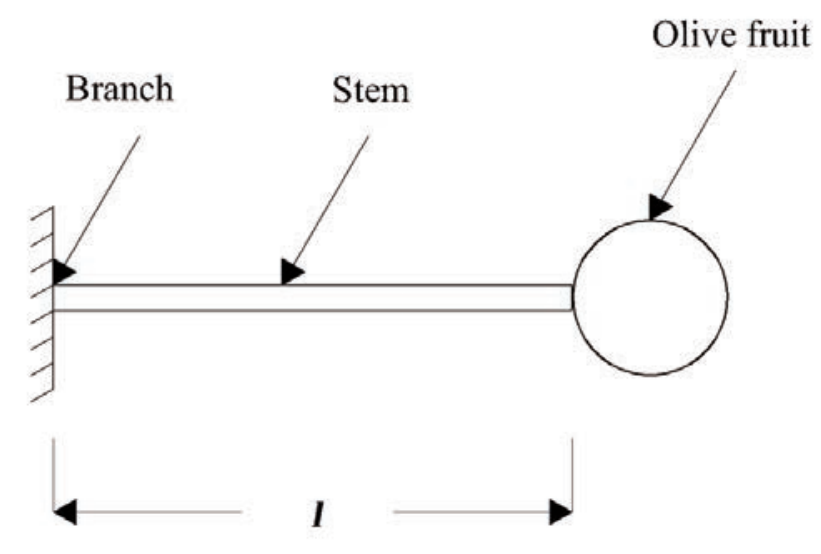

Figure 2. Structural system of the fruit stem system for olive. 
is the load at the end. This model considered only spring-mass behaviour and neglected both viscous and viscoelastic effects.

Ciro (2001) made their analysis based on the assumption that the distance to the centre of the load (the centre of the olive fruit) is $(l+r)$ where $l$ is the length of the stem and $r$ is the fruit radius. In this case, the stem elasticity constant $\left(K_{2}\right)$ can be calculated using Equation (3).

$$
K_{2}=K_{1}\left(\frac{l}{l+r}\right)^{3}
$$

Where:

$K_{2}=$ Elasticity constant of stem, $\mathrm{N} \cdot \mathrm{m}^{-1}$;

$l=$ Stem length, $\mathrm{m}$;

$r=$ Fruit radius, $\mathrm{m}$. 2016).

The natural frequency was calculated using Equation (4), (Cai,

$$
\left(F_{N}\right)_{i}=\frac{1}{2 \pi} \sqrt{\frac{K_{i}}{m}}
$$

Where:

$F_{N}=$ Natural frequency of the fruit stem system, $\mathrm{Hz}$;

$K_{i}=$ Elasticity constant of stem, $\mathrm{N} \cdot \mathrm{m}^{-1}$;

$i=1$ or 2 ;

$m=$ Fruit mass, $\mathrm{kg}$.

\section{Two degrees of freedom model (T.D.F.M)}

The two degrees of freedom model (T.D.F.M) according to Martinez (1977) was used to determine the natural frequency $\left(F_{N}\right)$ of the fruit stem system. This model (Figure 3) focuses on the elastic properties of the stem and mass second moment of the fruit. The stem is considered a cylindrical beam and the fruit stem joint is considered rigid. Both the mass and damping of the stem are negligible. The Martinez model is valid for small rotation angles; the model also describes the movement of the fruit stem as follows:

$$
\phi_{f}=\omega^{2} \frac{D}{C} \cdot \frac{a}{G}
$$

Where:

$\phi_{f}=$ Angular rotation of the fruit around its stem joint, rad;

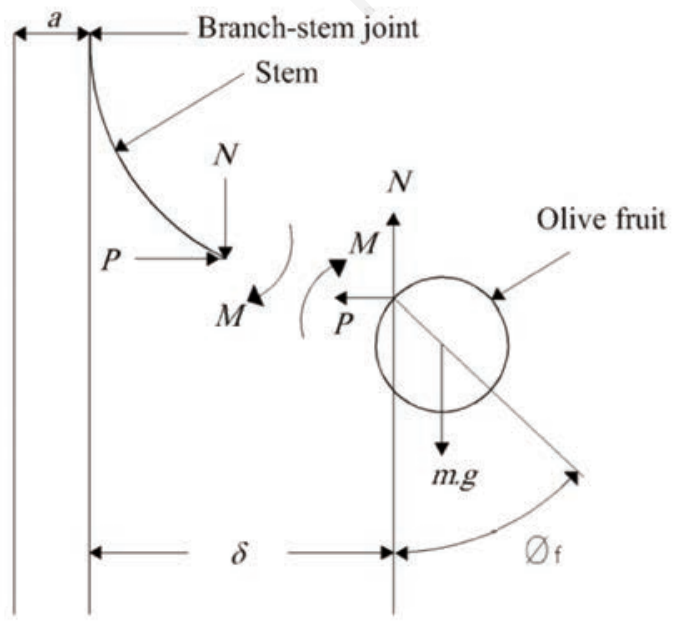

Figure 3. Martinez model of two degree of freedom (Ciro, 2001). $\omega=$ External frequency applied to branch or tree, $\operatorname{rad} \cdot \mathrm{s}^{-1}$;

$C, D, G=$ Empirical constants that depend on the physical properties of the fruit stem system;

$a=$ Amplitude applied to branch, $\mathrm{m}$.

$$
\delta=\left(\frac{\omega^{2}}{A}-\omega^{4} \cdot \frac{1-(B * D)}{A * C}\right) \cdot \frac{a}{G}
$$

Where:

$\delta=$ Horizontal displacement of the fruit stem system, m;

$A, B=$ Empirical constants that depend on the physical properties of the fruit stem system.

$N=\left(m * r * \omega^{2}\left(\omega^{2} \frac{D}{C}\right)^{2} * \frac{a}{G}\right)+(m \cdot g)$

Where:

$N=$ Normal force affecting the fruit stem joint, $\mathrm{N}$; $g=$ Gravity value, $\mathrm{m} \cdot \mathrm{s}^{-2}$.

\section{Third stage: experimentall tests}

Olive branches were vibrated using a hook type branch-shaker. The vibrating unit (Figure 4) of the used shaker was equipped with a three holes circular disk for amplitude adjustments. These branches were chosen in a critical stage of maturity (contains fullripe, half-ripe and full mature stage). Nylon nets were fixed on stands for receiving the removed fruits.

The tested values of frequency were chosen by averaging the maximum and the minimum values of natural frequency at each maturity level for each S.D.F.M and T.D.F.M. Then, three frequencies were chosen to cover the whole range of the resulting frequencies. While, the tested values of amplitude applied to the branch were 25, 30 and $35 \mathrm{~mm}$ according to O'brien et al. (1983). The rotating disk added to the vibrating unite of the shaker had 3 holes that were used to adjust the amplitude. The tested value of vibration time was $10 \mathrm{~s}$.

Through this research, two evaluating criteria were used. These criteria were fruit removal percentage $(F R P)$ and Degree of full-ripe fruit selectivity $(D S)$. The $F R P$ (Equation 8 ) is the percentage of the number $\left(N_{l}\right)$ of harvested olive fruits from one branch to the total number $\left(N_{2}\right)$ of olive fruits on the same branch.

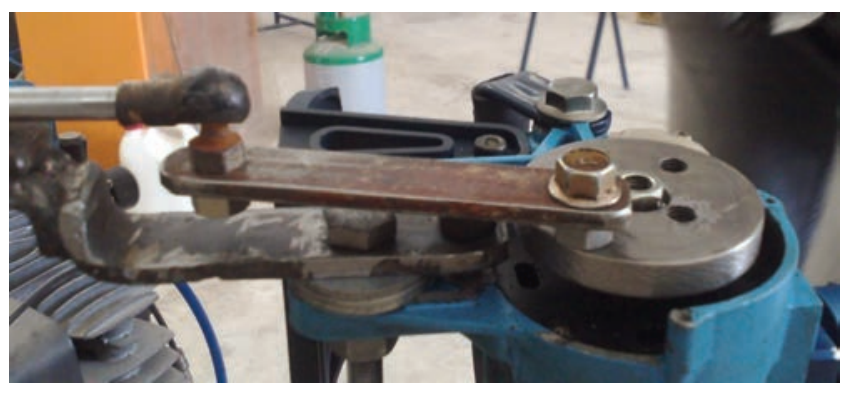

Figure 4. Photograph of vibrating unit. 
$F R P=\frac{N_{1}}{N_{2}} \times 100$

While, the $D S$ (equation 9) is the percentage of the number $\left(N_{3}\right)$ of harvested full-ripe olive fruits from one branch to the total number $\left(N_{4}\right)$ of full-ripe olive fruits on the same branch. This criterion is important for determining the vibrator operating parameters (frequency and amplitude) for oil olive small farms, which spread widely in many countries of the Middle East. On these small farms, only full-ripe fruits are desired for harvesting, accordingly, these farms are harvested two or three times per harvesting season.

$$
D S=\frac{N_{3}}{N_{4}} \times 100
$$

Also, the effect of mechanical harvesting on the trees were determined. The status of mechanically harvested trees was monitored for the 2017 and 2018 seasons. These observations included leaf status (yellowing or falling leaves), main and subsidiary branches (fractures in the main or subsidiary branches of the tree), tree productivity, and bruises to the spines at the contact point of the vibrator clutch with the branch.

\section{Results}

\section{Physical and mechanical properties of olive fruit stem systems}

The average values of olive fruit mass, fruit length, fruit width, bulk density, and stem length are presented in Table 1. It is clear that higher values of CV (more than 11\%) were accompanied with the properties of fruit mass, fruit length, fruit width, and stem length, while lower values of $\mathrm{CV}$ (less than 6\%) were obtained with the bulk density of olive fruit. For the properties of fruit mass, fruit width and stem length, there were significant differences between full mature stage and both half-ripe and full-ripe fruits while, there were no significant differences between half-ripe and full-ripe fruits. In the case of fruit length and bulk density, there were no significant differences between all the stages Table 1 . Based on the statistical analysis results it was assumed that the olive fruit stem systems would have different natural frequencies according to the maturity level.

Table 2 shows that the elasticity constants $\left(K_{l}\right.$ and $\left.K_{2}\right)$ and the stem rigidity value " $E I$ " decreased with increasing fruit maturity level. The coefficients of variation of these properties were higher than $22 \%$. This high variation in the results may be because the S.D.F.M neglect the viscous and viscoelastic effects of the olive fruit stem system. All values of $\left(K_{l}\right.$ and $\left.K_{2}\right)$ and " $E I$ " had significant differences between all maturity levels.

\section{Natural frequencies of the olive fruit stem system}

The natural frequencies of the fruit stem system using S.D.F.M. are shown in Table 3. For all maturity level, the minimum frequency values were at $K_{2}$ and the maximum values were at $K_{1}$. There was a decrease in natural frequency with increasing fruit maturity level. There is an overlapping frequency ranging from 13.41 to $43.58 \mathrm{~Hz}$. Also, the average values of natural frequency were $34.84,32.33$ and $26.92 \mathrm{~Hz}$ for full mature stage, half-ripe and fullripe fruits, respectively.

Table 4 shows the natural frequencies of the fruit stem system using Martinez's model (T.D.F.M). The variations in the minimum

Table 1. Physical properties of the olive fruit stem system.

\begin{tabular}{lcccccc} 
Property & \multicolumn{2}{c}{ Full mature stage } & \multicolumn{2}{c}{ Half-ripe } & \multicolumn{2}{c}{ Full-ripe } \\
& Mean value (SE) & CV & Mean value (SE) & CV & 14.65 & $5.14 \pm 0.07$ \\
Fruit mass, $g$ & $4.16 \pm 0.05$ & 11.46 & $5.13 \pm 0.08$ & 16.17 & $23.18 \pm 0.43$ \\
Fruit length, $\mathrm{mm}$ & $22.81 \pm 0.43$ & 18.66 & $23.02 \pm 0.37$ & 13.54 & 18.32 \\
\hline Fruit width, $\mathrm{mm}$ & $16.39 \pm 0.24$ & 14.45 & $16.67 \pm 0.39$ & 23.56 & $16.88 \pm 0.33$ \\
Bulk density, $\mathrm{g} \cdot \mathrm{cm}^{-3}$ & $0.58 \pm 0.003$ & 6.02 & $0.57 \pm 0.002$ & 3.87 & $0.58 \pm 0.002$ \\
\hline Stem length, $\mathrm{mm}$ & $22.21 \pm 0.36$ & 16.38 & $25.45 \pm 0.44$ & 17.37 & $25.52 \pm 0.47$ \\
\hline
\end{tabular}

$\mathrm{SE}$, standard error (difference between two means $\geq$ SE indicates significant difference); CV, coefficient of variation (standard deviation divided by the mean value).

Table 2. Mechanical properties of the olive fruit stem system.

\begin{tabular}{|c|c|c|c|c|c|c|}
\hline \multirow{2}{*}{ Condition of the olive fruit } & \multicolumn{4}{|c|}{ Elasticity constants, $\mathrm{N} \cdot \mathrm{m}^{-1}$} & \multicolumn{2}{|c|}{ Stem rigidity $(E I), \mathrm{N} \cdot \mathrm{m}^{2}$} \\
\hline & $K_{1}(\mathrm{SE})$ & CV & $K_{2}(\mathrm{SE})$ & CV & Value (SE) & CV \\
\hline Full mature stage & $131.2 \pm 2.93$ & 22.3 & $74.6 \pm 1.84$ & 24.6 & 4.94E-04+1.16E-05 & 23.4 \\
\hline Half-ripe & $123.2 \pm 3.19$ & 25.9 & $66.4 \pm 1.53$ & 23.1 & $4.78 \mathrm{E}-04 \pm 9.70 \mathrm{E}-06$ & 20.3 \\
\hline Full-ripe & $94.8 \pm 2.12$ & 22.3 & $52.5 \pm 1.18$ & 22.5 & $3.79 \mathrm{E}-04 \pm 8.07 \mathrm{E}-06$ & 21.3 \\
\hline
\end{tabular}

SE, standard error (difference between two means $\geq$ SE indicates significant difference); CV, coefficient of variation (standard deviation divided by the mean value).

Table 3. Natural frequencies of fruit stem system using single-degree of freedom model.

\begin{tabular}{|c|c|c|c|c|c|}
\hline \multirow[t]{2}{*}{ Condition of the olive fruit } & \multicolumn{4}{|c|}{ Natural frequency, $\mathrm{Hz}$} & \multirow[b]{2}{*}{ Average } \\
\hline & Minimum (SE) & CV & Maximum (SE) & CV & \\
\hline Full mature stage & $13.41 \pm 0.44$ & 32.54 & $56.27 \pm 1.64$ & 29.17 & 34.84 \\
\hline Half-ripe olive & $12.18 \pm 0.25$ & 20.88 & $52.48 \pm 1.12$ & 21.34 & 32.33 \\
\hline Full-ripe olive & $10.25 \pm 0.20$ & 19.72 & $43.58 \pm 0.98$ & 22.53 & 26.92 \\
\hline
\end{tabular}

$\mathrm{SE}$, standard error (difference between two means $\geq \mathrm{SE}$ indicates significant difference); CV, coefficient of variation (standard deviation divided by the mean value). 
values of natural frequencies were small but these variations were high in the maximum values (differences of about $4.85 \mathrm{~Hz}$ ). Hence, theoretically, a good degree of selectivity could be obtained if the olive branch or olive tree vibrates at the maximum frequencies. From Tables 3 and 4 it is clear that the average $F_{N}$ values were $33.9,31.9$, and $28.0 \mathrm{~Hz}$ for full mature stage, half-ripe olive and full-ripe olive respectively.

\section{Olive fruit stem dynamic system}

To simulate the angular rotation $\left(\phi_{f}\right)$ of olive fruit around its stem joint, the horizontal displacement $(\delta)$ of the fruit stem system and normal force $(N)$ affecting the fruit stem joint, the constant values $A, B, C, D$ and $G$ were determined using Martinez's model.

The constant values $A, B, C, D$ and $G$ for full-ripe fruits were $2.23 \mathrm{E}+06,0.032,3.90 \mathrm{E}+05,120$ and 0.392 , respectively.

The values of $\phi_{f}, \delta$ and $N$ at external frequencies of 25,30 and $35 \mathrm{~Hz}$ and amplitudes applied to branch of 25,30 and $35 \mathrm{~mm}$ are shown in Figure 5. It is clear that the angular rotation $\left(\phi_{f}\right)$ of olive fruit around its stem joint was increased by increasing the amplitude and frequency. The maximum value of $\phi_{f}$ was $1.08^{\circ}$ at frequency of $35 \mathrm{~Hz}$ and amplitude of $35 \mathrm{~mm}$. The minimum value of $\phi_{f}$ was $0.27^{\circ}$ at frequency of $25 \mathrm{~Hz}$ and amplitude of $25 \mathrm{~mm}$. At 25 mm amplitude, the $\phi_{f}$ increased by 16.64 and $34.56 \%$ when the frequency increased from 25 to $30 \mathrm{~Hz}$ and $35 \mathrm{~Hz}$, respectively. The same trend was found at amplitude of 30 and $35 \mathrm{~mm}$.

Also, from Figure 5 it is clear that the value of angle $\phi_{f}$ is small in the tested range of amplitude and frequency. This result is accepted with the basic of Martinez's model which is valid for the small rotation angles.

From Figure 5 it is also clear that the horizontal displacement $(\delta)$ of the fruit stem system increased by increasing the amplitude and frequency. The maximum value of $\delta$ was $9.7 \mathrm{~mm}$ at frequency of $35 \mathrm{~Hz}$ and amplitude of $35 \mathrm{~mm}$. The minimum value of $\delta$ was $2.4 \mathrm{~mm}$ at frequency of $25 \mathrm{~Hz}$ and amplitude of $25 \mathrm{~mm}$. At $25 \mathrm{~mm}$ amplitude, the $\delta$ increased by 12.4 and $34.04 \%$ when the frequency increased from 25 to $30 \mathrm{~Hz}$ and $35 \mathrm{~Hz}$, respectively. The same trend was found at amplitude of 30 and $35 \mathrm{~mm}$.

The normal force $(N)$ affecting the fruit stem joint was increased by increasing the amplitude and frequency. The maximum value of $N$ was $15.3 \mathrm{~N}$ at frequency of $35 \mathrm{~Hz}$ and amplitude of $35 \mathrm{~mm}$. The minimum value of the normal force $(N)$ affecting the fruit stem system was $2.2 \mathrm{~N}$ at frequency of $25 \mathrm{~Hz}$ and amplitude of $25 \mathrm{~mm}$. The normal force values increased by (94.6, and $188.71 \%)$, (96.37 and 192.73\%) and (97.60 and 195.21\%) when the amplitude increased from 25 to $30 \mathrm{~mm}$ and $35 \mathrm{~mm}$ at frequency of 25, 30 and $35 \mathrm{~Hz}$, respectively. At amplitude of $25 \mathrm{~mm}$, the $N$ increased by 55.37 and $135.53 \%$ when the frequency increased from 25 to $30 \mathrm{~Hz}$ and $35 \mathrm{~Hz}$, respectively. The same trend was found at amplitude of 30 and $35 \mathrm{~mm}$.

\section{Field experiment results}

Vibration frequencies of 25, 30 and $35 \mathrm{~Hz}$, amplitudes of vibration at the location of the vibrator of 25,30 and $35 \mathrm{~mm}$, and time of vibration of $10 \mathrm{~s}$ were selected for field experiments. From Figure 6 it is clear that the fruit removal percentage (FRP) of olive fruits increased with increasing frequency from 25 to $35 \mathrm{~Hz}$ at all tested amplitude values.

The maximum FRP, $90.6 \%$, was achieved at frequency of 35 $\mathrm{Hz}$ and amplitude of $25 \mathrm{~mm}$. While the minimum FRP, 78.69\%, was found at frequency of $25 \mathrm{~Hz}$ and amplitude of $25 \mathrm{~mm}$. At 25 $\mathrm{Hz}$ frequency, the maximum $F R P, 80.0 \%$, was achieved at amplitude of $35 \mathrm{~mm}$. At $30 \mathrm{~Hz}$ frequency, the maximum $F R P, 84.6 \%$,

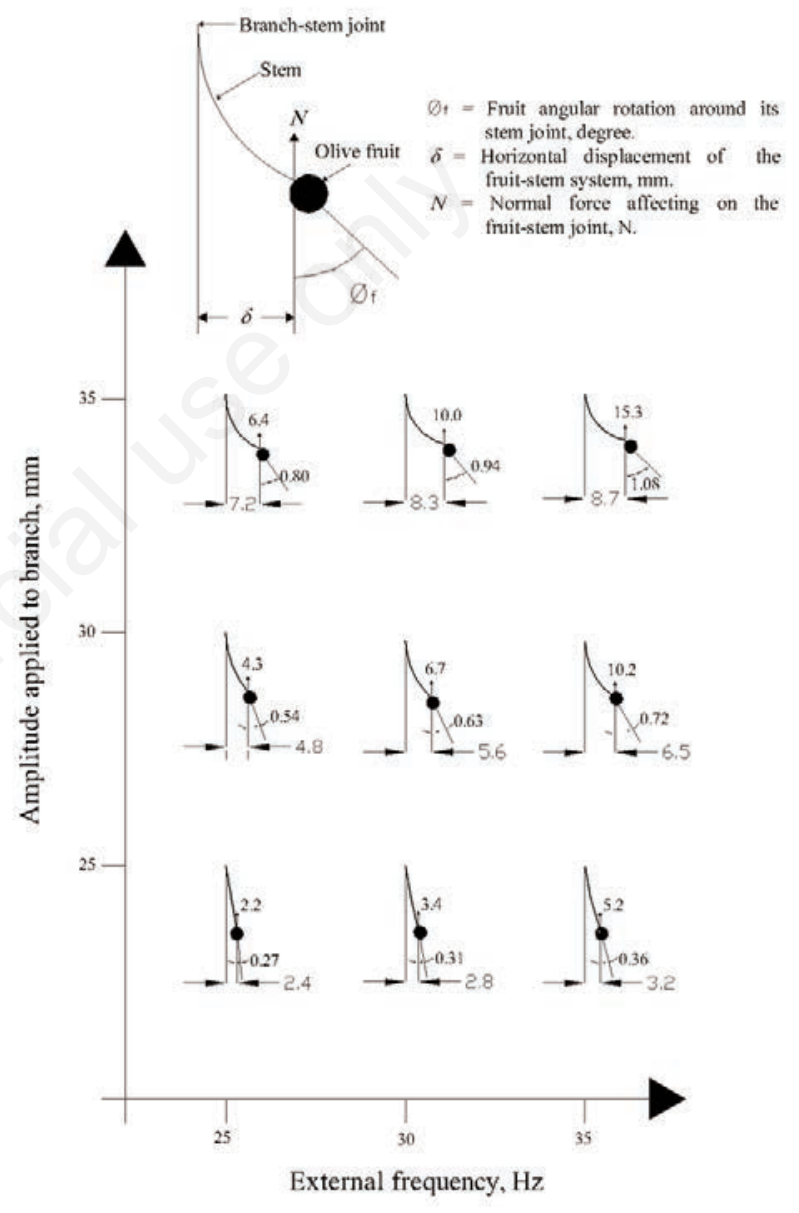

Figure 5. Effect of frequency and amplitude on the horizontal displacement $(\delta)$ angular rotation of fruit $\left(\phi_{f}\right)$ and normal force affecting the fruit stem joint $(\mathrm{N})$.

Table 4. Natural frequencies of the fruit stem system using the two-degree of freedom model (Martinez model).

\begin{tabular}{|c|c|c|c|c|c|}
\hline \multirow[t]{2}{*}{ Condition of the olive fruit } & \multicolumn{4}{|c|}{ Natural frequency, $\mathrm{Hz}$} & \multirow[b]{2}{*}{ Average } \\
\hline & Minimum (SE) & CV & Maximum (SE) & CV & \\
\hline Full mature stage & $13.29 \pm 0.19$ & 14.62 & $52.57 \pm 1.13$ & 21.44 & 32.93 \\
\hline Half-ripe olive & $12.11 \pm 0.29$ & 24.17 & $50.83 \pm 1.44$ & 28.33 & 31.47 \\
\hline Full-ripe olive & $10.50 \pm 0.18$ & 16.95 & $47.72 \pm 0.90$ & 18.92 & 29.11 \\
\hline
\end{tabular}

SE, standard error (difference between two means $\geq$ SE indicates significant difference); CV, coefficient of variation (standard deviation divided by the mean value). 
was achieved at amplitude of $30 \mathrm{~mm}$. While, at $35 \mathrm{~Hz}$ frequency, the maximum $F R P, 90.6 \%$, was achieved at amplitude of $25 \mathrm{~mm}$. Thus, it could be concluded that the FRP increased by increasing the frequency and decreasing the amplitude.

Increasing the frequency from 25 to $35 \mathrm{~Hz}$ led to an increase in the normal force affecting the fruit stem joint, which consequently increased the possibility of fruit separation, which ultimately increased FRP. Some full mature stage and half-ripe fruits fell with the full-ripe fruit. This may be caused by the non-significant differences between the full mature, half-ripe and full-ripe stages in fruit length and bulk density. In addition, there was a non-significant difference between half-ripe and full-ripe fruits in fruit mass, fruit width and stem length. The average values of fruit degree of selectivity $(D S)$ for full-ripe olive fruits are shown in Figure 6. It is clear that the values of $D S$ for the same frequency were decreased by increasing the amplitude. The minimum value of $D S$ was $65.62 \%$ at frequency of $35 \mathrm{~Hz}$ and amplitude of $35 \mathrm{~mm}$. While, the maximum value of $D S$ was $78.58 \%$ at $25 \mathrm{~Hz}$ and amplitude of 25 $\mathrm{mm}$. The degree of selectivity $(D S)$ for full-ripe olive is not up to 100 percent at these frequencies, due to the physical properties overlapping of the fruit and fruit stem between the different maturity stages where the $\mathrm{CV}$ value for the full-ripe fruit stem length was $18.34 \%$. From Figures 6 and 7, it is clear that the maximum FRP, $90.6 \%$, was achieved at $35 \mathrm{~Hz}$ frequency and $25 \mathrm{~mm}$ amplitude while the maximum $D S, 78.58 \%$, was achieved at $25 \mathrm{~Hz}$ frequency and $25 \mathrm{~mm}$ amplitude.

\section{Status of mechanically harvested trees}

There was no noticeable damage on the trees that were mechanically harvested compared to the rest of the orchard trees. No apparent damage or bruising were noticed on the branches under the clamps of the shaker, but very small bruising were detected when the branches were accurately examined. These bruising may affect the phloem blocking its' downward transportation of hormones and carbohydrates as a results these compounds will be diffused into the xylem then transported to leaves and reproduction tissues. Bruising and griddling may positively affect ethylene which stimulates the induction of the floral buds and improve flowering in the following season. An increase in flower initiation following possible phloem blockage due to vibrating action, is usually evident in the season following treatment (Khandaker et al., 2011; Gawankar et al., 2019).

\section{Discussion}

Successful Olive mechanical harvesting depends on determining the optimum vibrator operating parameters; frequency and amplitude (O'brien et al., 1983). Several methods can be used to determine the optimum operating parameters (Cini and Catalano, 1996; Ciro, 2001; Sola-Guirado et al., 2016). Both S.D.F.M and T.D.F.M were effective in predicting suitable harvester operating parameters. In this research, S.D.F.M and T.D.F.M were used to determine the suitable natural frequency $\left(N_{F}\right)$ of the fruit stem system for harvesting the maximum possible amounts of full-ripe olive with the highest possible fruit selectivity and minimal damage to the tree. These results indicated that the natural frequency ranged between 25 and $35 \mathrm{~Hz}$. The field tests were conducted using three frequencies to cover the whole range of the models resulting in frequencies with an amplitude values of 25, 30, and 35 mm (O'brien et al., 1983). The field results showed that the FRP ranged from 78.69 to $90.60 \%$ and increased with increasing both the frequency and the amplitude. This can be attributed to the increase of the force acting on the fruit stem with the increase of both the frequency and the amplitude thus increasing the bending moment on the stem and causing the fruit detachment. These results are similar to those found by Polat et al. (2017), who reported that the FRP was $93.27 \%$ at a frequency of $40 \mathrm{~Hz}$ and $20 \mathrm{~mm}$ amplitude. El Attar et al. (2004) found that the top portion of the olive tree can be harvested using $22 \mathrm{~Hz}$ frequency and $10 \mathrm{~cm}$ displacement but the lower parts of the tree needed more displacement and less frequency, they suggested that the shaker should be designed to give different frequencies and amplitudes. Knowing that most of the olive farms in the Middle East are small farms and the standard practice is to maintain as much yield as possible. It is usually in such farms to harvest the ripe fruits several times during the harvesting season (mainly manually now). If mechanical harvesting is used, the selectivity of the fruits will affects the quality of the resulting oil extraction. The degrees of selectivity values were ranged from 65.62 to $78.58 \%$, and at the same frequency. The $D S$ values decreased with the increase of the amplitude, this may be due to the increase of the bending moment on the fruit with the increase of the amplitude, thus detaching more fruits that are not fully ripe. The highest $D S$ value was achieved at $25 \mathrm{~Hz}$ and $25 \mathrm{~mm}$ amplitude.

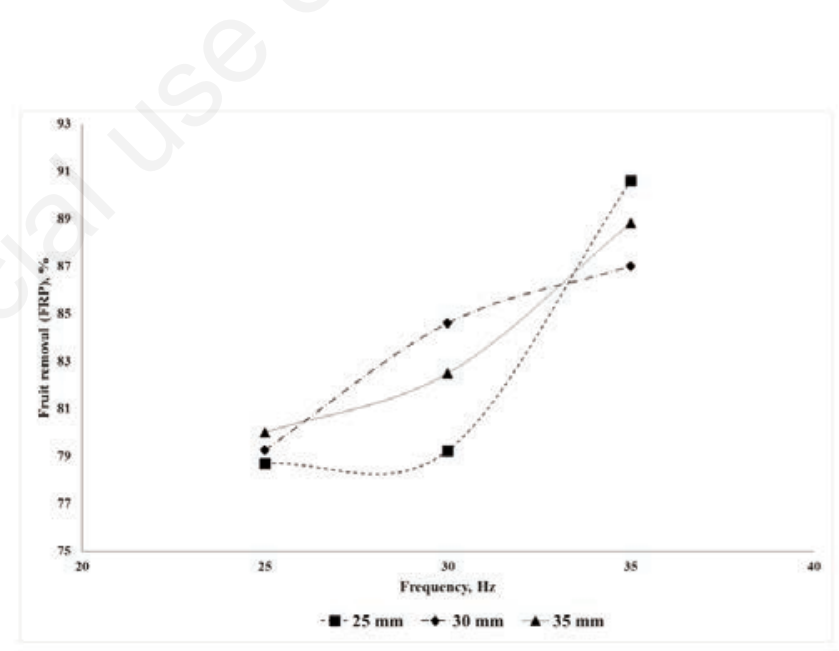

Figure 6. Effect of frequency on the olive removal percentage at different amplitudes.

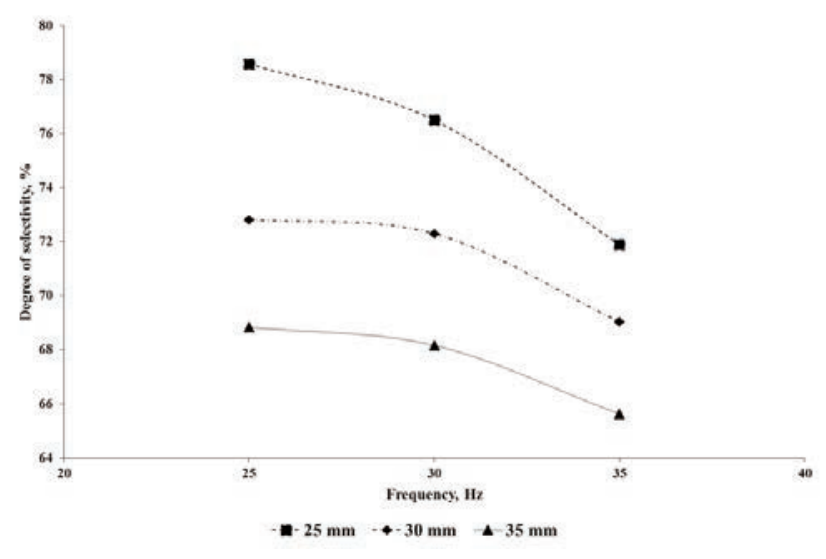

Figure 7. Degree of selectivity of full-ripe olive fruits as a function of amplitude and frequency. 


\section{Conclusions}

From this investigation, it could be concluded that: i) Both fruit stem elasticity constant and stem rigidity decreased with increasing fruit maturity; ii) The average value of natural frequency for full-ripe fruits using the single degree of freedom model and two degrees of freedom model was $28 \mathrm{~Hz}$; iii) The maximum fruit removal percentage value, $90.6 \%$, was achieved at frequency of 35 $\mathrm{Hz}$ and an amplitude of $25 \mathrm{~mm}$; iv) The maximum value of the degree of selectivity for full-ripe olive fruits was $78.58 \%$ at a frequency of $25 \mathrm{~Hz}$ and amplitude of $25 \mathrm{~mm}$; v) No damage was observed on the trees that were mechanically harvested compared to the other orchard trees.

The suitable olive fruit removal percentage with the maximum degree of selectivity can be realised when the vibrator is operating at a $25 \mathrm{~mm}$ amplitude and $25 \mathrm{~Hz}$ frequency. Under these conditions, the fruit removal percentage was $78.69 \%$ and the degree of selectivity for full-ripe olive was $78.58 \%$.

\section{References}

Aiello G, Vallone M, Catania P, 2019. Optimising the efficiency of olive harvesting considering operator safety. Biosyst. Engine. 185:15-24.

Bacenetti J, De Luca AI, 2018. Harvesting system sustainability in Mediterranean olive cultivation. Sci. Total. Environ. 625:1446-58.

Beghi R, Giovenzana V, Guidetti R, Cappelli A, D’Antoni A, Menditto N, Cini E, 2017. Exploitation of technological innovations along the olive oil milling process for an optimisation of the plant performance. pp 285-288 in International AIIA Conference, Università degli studi di Bari Aldo Moro, Bari, Italy.

Cai LW, 2016. Fundamentals of mechanical vibrations. John Wiley \& Sons, New York, USA.

Cappelli A, Parretti C, Cini E, Citti P, 2019. Development of a new washing machine in olive oil extraction plant: A first application of usability-based approach. J. Agricult. Engine. 50:134-42.

Castro-García S, Castillo-Ruiz FJ, Sola-Guirado RR, JiménezJiménez F, Blanco-Roldán GL, AgüeraVega J, Gil-Ribes JA, 2014. Table olive response to harvesting by trunk shaker. ref. C0662 in International Conference on Agricultural Engineering, 6-10 July, Zurich, Switzerland.

Catalano P, Fucci F, Giametta F, La Fianza G, Bianchi B, 2013. Vibration analysis using contactless acquisition system. Sensing Technologies for Biomaterial, Food and Agriculture. Naoshi Kondo, Proc. of SPIE, 8881:888108, pp. 1-7.

Cicek G, 2011. Determination of harvesting costs and cost analysis for different olive harvesting methods. J. Food Agric. Environ. 9:201-4.

Cini E, Catalano P, 1996. Un metodo per lo studio nel dominio del tempo delle vibrazioni nella meccanica agraria. Riv. Ing. Agr. 2:65-72.

Ciro VHJ, 2001. Coffee harvesting I: Determination of the natural frequencies of the fruit stem system in coffee trees. Appl. Engine. Agricult. ASAE 17:475-9.

Deboli R, Calvo A, Preti C, Inserillo M, 2014a. Design and test of a device for acceleration reproducibility of hand-held olive harvesters. Int. J. Industr. Ergon. 44:581-9.

Deboli R, Calvo A, Gambella F, Preti C, Dau R, Casu EC, 2014b.
Hand arm vibration generated by a rotary pick-up for table olives harvesting. Agricult. Engine. Int. CIGR J. 16:228-35.

El Attar MZ, El Awady MN, Rashwan M, Genaidy MAI, 2004. Physical properties effects on shaker-model harvesting of olive-trees. pp 4-5 in $12^{\text {th }}$ Conference of Miser Society of Agricultural Engineering, Giza, Egypt.

Gawankar MS, Haldankar PM, Salvi BR, Parulekar YR, Dalvi NV, Kulkarni MM, Saitwal YS, Nalage NA, 2019. Effect of girdling on induction of flowering and quality of fruits in horticultural crops-a review. Adv. Agric. Res. Technol. J. III:201-15.

Ghonimy MI, 2006. Prediction of the suitable amplitude of shaking unit for fruit harvesting. Misr J. Ag. Eng. 23:1-18.

Guzmán E, Baeten V, Pierna JAF, García-Mesa JA, 2015. Determination of the olive maturity index of intact fruits using image analysis. J. Food Sci. Technol. 52:1462-70.

Hoshyarmanesh H, Dastgerdi HR, Ghodsi M, Khandan R, Zareinia $\mathrm{K}, 2017$. Numerical and experimental vibration analysis of olive tree for optimal mechanized harvesting efficiency and productivity. Comput. Electron. Agricult. 132:34-48.

Karimi D, Rashvand M, Shokrian A, 2019. Effect of road vibrations on the mechanical properties of olive fruit during transport. Am. J. Mechan. Appl. 7:30-4.

Khandaker MM, Hossain AS, Osman N, Boyce AN, 2011. Application of girdling for improved fruit retention, yield and fruit quality in Syzygium samarangense under field conditions. Int. J. Agric. Biol. 13:18-24.

Leone A, Romaniello R, Tamborrino A, Catalano P, Peri G, 2015. Identification of vibration frequency, acceleration, and duration for efficient olive harvesting using a trunk shaker. Trans. ASABE 58:1-8.

Martinez A, 1977. Estudio teórico de la dinámica del sistema fruto pedúnculo. Revista Ciencias Técnicas. Serie construcción de maquinaria. Instituto Superior Politécnico José Antonio Echeverría, Habana, Cuba. Octubre. 14-16 pp.

O'brien M, Cargill BF, Fridley RB, 1983. Principles and Practices for Harvesting \& Handling Fruits and Nuts. AVI bub. Comp, INC., Westport, CT, USA.

Polat R, Güner M, Erdoğan D, Gezer İ, Atay Ü, Aktaş T, 2017. Determination of optimum shaking frequency and amplitude of prototype body shaker used for mechanical harvesting of pistachio. pp 597-603 in Proceedings of the 45th International Symposium on Agricultural Engineering, Actual Tasks on Agricultural Engineering, 21-24 February 2017, Opatija, Croatia.

Sola-Guirado RR, Jiménez-Jiménez F, Blanco-Roldán GL, CastroGarcía S, Castillo-Ruiz FJ, Gil-Ribes JA, 2016. Vibration parameters assessment to develop a continuous lateral canopy shaker for mechanical harvesting of traditional olive trees. Spanish J. Agric. Res. 14:e0204.

Tamborrino A, Squeo G, Leone A, Paradiso VM, Romaniello R, Summo C, Caponio F, 2017. Industrial trials on coadjuvants in olive oil extraction process: effect on rheological properties, energy consumption, oil yield and olive oil characteristics. J. Food Engine. 205:34-46.

Zipori I, Dag A, Tugendhaft Y, Birger R, 2014. Mechanical harvesting of table olives: harvest efficiency and fruit quality. Hortsci. 49:55-8. 